Marquette University

e-Publications@Marquette

7-1-2006

\title{
Marketing, Consumers and Technology: \\ Perspectives for Enhancing Ethical Transactions
}

Gene R. Laczniak

Marquette University, eugene.laczniak@marquette.edu

Patrick Murphy

University of Notre Dame

Accepted version. Business Ethics Quarterly, Vol. 16, No. 3 (July 2006): 313-321. DOI. (C) 2006 Cambridge University Press. Used with permission. 


\title{
Marketing, Consumer and Technology: Perspectives for Enhancing Ethical Transactions
}

Authors: Gene R. Laczniak \& Patrick E. Murphy

\begin{abstract}
The advance of technology has influenced marketing in a number of ways that have ethical implications. Growth in use of the Internet and e-commerce has placed electronic "cookies," spyware, spam, RFIDs, and data mining at the forefront of the ethical debate. Some marketers have minimized the significance of these trends. This overview paper examines these issues and introduces the two articles that follow. It is hoped that these entries will further the important "marketing and technology" ethical debate.
\end{abstract}

Any casual survey of the twenty-first-century marketplace reveals an economic landscape of robust e-commerce and numerous emergent forms of technologically assisted marketing. An observer of this scene might assert for good reason that marketers are increasingly leveraging their new technology to erode the consumers' right to autonomy (Kelly and Rowland 2000). A number of these current technology aided practices are problematic in terms of their potential invasiveness (Marshall 1999), their violations of consumer privacy rights (Hemphill 2002) or simply their added disadvantage to consumers (Gordon 2002).

Consider just the following illustrations:

- E-Commerce Cookies and Spyware. When consumers log on to a website to seek purchase information or to conduct an online transaction, a "cookie" might he placed on their personal computers, allowing sellers to track movements on that and perhaps other Internet sites visited (Linn 2004). When consumers download software, part of the usage agreement (which often consumers fail to read due to its intentional length and complexity) sometimes includes the acceptance of shadow software that records site surfs and targets pop-up ads at these users. In these ways, marketers gather considerable information about how consumers traverse the web and in what specific sequence their purchase decision unfolds. A recent development regarding cookies is that more companies are only using first party cookies (put on by the site visited) and resisting third party cookies (placed by an outside company) to increase consumer trust (Kesmodel 2005).

1 Laczniak \& Murphy 
- Spam. One of the least satisfying dimensions of the growing e-commerce environment is spam - unsolicited email that typically attempts to sell products and services to Internet users. The most irritating forms of such spam include advertisements for easy (high cost) financing, gambling sites, pornographic material and diet supplements. Worse, sometimes as consumers open spam message attachments to ascertain their nature, instructions are introduced to the computer "page jacking" users to a seller's website and possibly "mouse trapping" them so that efforts to electronically escape from that site dump them to a related site or a revised form of the original solicitation. Worse still, buyers receive faux messages from purportedly known business partners (a practice known as "phishing") asking the receiver to verify personal information that if rendered will aid identity theft (Borzo 2004). It is estimated that approximately 50 percent of all emails received can be categorized as spam (Swartz 2004). The Controlling the Assault of Non-Solicited Pornography and Marketing Act of 2003 (CAN-SPAM) went into effect in January 2004 and required companies to conspicuously label their commercial e-mails and provide clear methods to opt out of future ads (Chang 2004). Despite this legislation, consumer frustration with spam, along with lost personal and organizational productivity, has grown to alarming proportions (Davidson 2004; Friel 2005).

- RFIDs. Another technology on the ascendance involves RFIDs or radio frequency identification tags. Diffusion of this technology could also engender significant consumer privacy concerns and raise ethical questions (Covert 2004; Peslak 2005). RFIDs are millimeter-wide microchips (about the size of a match head) that can contain a substantial amount of data about the product in which it is imbedded. The microchip has the capacity to send out that information via wireless signal to a radio scanner. This is the same technology currently used for some drive-by toll booth passes as well as for quick gasoline purchases via electronic "key chain fob" rather than credit card swipe. Currently, RFIDs are used mainly for internal inventory tracking and control. For example, Wal-Mart uses this technology in its distribution centers and is requiring that it be incorporated by all its suppliers in the next couple of years (Feder 2003). Wal-Mart is getting some "push back" on this demand from suppliers primarily due to cost considerations (Hays 2004). And Pfizer is utilizing

\section{Laczniak \& Murphy}


RFIDs to guarantee that certain of its drug products (e.g., Viagra) have not been counterfeited (Appleby 2004). However, as RFID technology becomes more widely applied and refined, it could potentially provide marketing researchers with the capability to "enter" a consumer's home or garage and, given the proper scanner-receivers, identify the nature, amount, and source of many of the products contained therein (Hajewski 2003).

- Data Mining. Market researchers are also accumulating, via computerized files, an increasing amount of information about their customers. Given the compiling capabilities of database software, much of the information is aggregated from disparate buying situations. Made easier by widespread consumer acceptance of preferred buyer cards and credit purchasing, such information is combined using personal identifiers such as phone number, household address, driver's license registration or even social security number (Loveman 2003). Then using "data mining" techniques-sophisticated multi-variable statistical models that can extract scattered information from large consumer data pools-marketers are able to construct individual consumer profiles for millions of shoppers (Berson et al. 2000; Murphy, et al. 2005). Disturbingly, these profiles are then copied and sold to other marketers who use it to predict likely purchase prospects for their goods and services. As a result, a growing and permanent record exists of what individual consumers buy, where they bought it, the price paid and the incentives that motivated the transaction. Amazingly, some marketers use this information to try to drive away consumers who they project will not be particularly profitable (McWilliams 2004).

Taking all of this into account, it is understandable that many consumers are troubled by certain technology aided marketing practices that might be construed as prying, irritating and exploitive. In fact, a 2003 Harris interactive poll of over one thousand U.S. adults found that 69 percent of respondents agreed that consumers have lost all control over how their personal information is collected and used (Loyle 2003). Some social observers have gone so far as to opine that privacy rights will be to the twenty-first century what civil rights and women's equality were to the twentieth.

It was with such concerns in mind that in the summer of 2003 the Business Ethics Quarterly issued a call for papers addressing ethical issues stemming from the technology and

\section{Laczniak \& Murphy}


marketing nexus. While privacy questions are the most obvious issue, erosion of other consumer rights such as access (e.g., the so-called digital divide), property (e.g., electronic copyrights), security (e.g., protection of sensitive consumer data by sellers), and redress (e.g., the ability to verify personal records) are increasingly being challenged by marketing approaches that rely heavily on the latest technologies. The ultimate economic and social ramifications of emergent marketing technology are uncertain, but it seems clear that many new ethical questions win arise. Thus, academic scholars were invited to provide their research based or analytic perspectives on any important dimension of such issues.

\section{Marketers' Defense of Ethical Criticism}

A perusal of the business and popular press suggests that marketing practitioners have already been mounting a defense to the perceived ethical criticisms of their new technologies. To illustrate this point, a few of the more common marketing apologetics are noted below.

- Marketing practitioners assert that when the effects of a marketing technology or its application become socially troubling, the existing regulatory framework responds by outlawing or suppressing the most annoying and harmful transgressions. They point to the 2003 institution of the federally administered national no call list that restricts telemarketers from contacting consumers that are signatories (Davidson 2003). If households listed on this roll are called (certain exceptions apply), telemarketers are subject to an $\$ 11,000$ fine per violation. It is estimated that this legislation, in conjunction with existing state programs, will eliminate up to 90 percent of all telemarketing calls. Marketers also highlight the thirty-three states that have laws regulating spam (Mangalindan 2003) as well as the federal 2004 "Can Spam" Act, which mandates that e-sellers cannot hide behind false addresses, thus making their identities more traceable. Consumer groups, however, characterize the Act's provisions as ineffective because among other things it does nothing to control the flow of spam from non-domestic e-sellers (Davidson 2004). Finally, marketers underscore the Children's Online Privacy Protection Act of 2002 as a model example of how well the current oversight system works (Lans-Retsky 2004). Known as COPPA, this legislation safeguards a particularly vulnerable group, children, from most forms of online marketing research. For example, COPPA makes it a violation for any marketer to knowingly gather online personal information from

\section{Laczniak \& Murphy}


children younger than thirteen years of age without specific parental consent. Already two major companies, Mrs. Fields Cookies and Hershey's (candy) Direct have incurred significant fines for COPPA violations (Loyle 2003). To date, COPPA is the only anti-privacy statute that has been passed in the United States.

- Marketers contend that the problems attributed to new selling technologies are overstated, not really novel and represent only slightly different forms of old practices that are already well tolerated by consumers. They observe that junk mail has long clogged household mailboxes; some consumers dislike it, others look forward to it. Marketers question how spam is any different than junk mail and recommend that consumers simply use the delete button more liberally (Goldman 2003). Furthermore, justifying their opinions with national survey data, marketers suggest there is great variability among consumers in their tolerance for direct selling (Milne and Rohm 2000). Marketers also argue that concerns about the privacy dimensions of RFID tagged products are widely overblown (Ody 2004). Yet in Texas, this technology is being used to track the movement of hundreds of young school children in order to provide a record that they entered or exited school buses and as an early warning sign of possible kidnapping (Richtel 2004),

- Marketers emphasize that some aspects of the much discussed consumer privacy debate may be exaggerated because many consumers are willing to give away personal information quite readily. For instance, the majority of consumers volunteer detailed demographic information on product warranty forms although only the most basic information (name and address) is required to activate the coverage for most products. Consumer acceptance of preferred shopper cards, used in exchange for various discounts and rewards at the sponsoring retailer, has never been stronger as buyers sign up in droves surely knowing that their every purchase is tracked in detail. And digital cable TV, tethered to interactive capability, is steadily increasing its subscriber base with customers presumably knowing that their viewing selections can be logged and classified. In short, many marketers believe that it is difficult to defend or even establish a scrupulous buyers' right to privacy when so many consumers signal by their actions that they simply don't mind sharing their personal information with vendors or at least are willing to hand it over in exchange

\section{Laczniak \& Murphy}


for minimal perks. Business philosophers have observed as much (De George 1999). As one privacy director remarked in response to privacy statutes: "Forget laws and standards-you need to send the right message to the right person at the right time" (Lager 2005: 35),

\section{Emerging Issues in Marketing and Technology}

Of course, blanket defenses for widely varying applications of marketing technology are not particularly useful. As is necessary when significant new technologies impact the economy, numerous questions arise, some of an ethical nature, that need to be systematically investigated. With this special issue on marketing and technology, Business Ethics Quarterly hopes to advance the conversation about some of these questions in an analytic and reasoned fashion. The articles contained in this issue build on some already existing foundational work. A partial list of such writing includes Caudill and Murphy 2000, Donaldson 2001, and Peace et al, 2002, as well as Kracher and Corritore 2004, This last paper makes a particularly significant point about e-commerce, suggesting that it requires not so much a new ethics but a dedicated evaluation of the new manifestations of economic exchange from various traditional ethical frameworks, Kracher and Corritore also make a particularly strong case for the centrality of trust as a solution to many of the emerging problems of the electronic marketplace. Such advocacy adds to the themes previously expressed by Grabner-Kraeuter (2002), Hemphill (2002) and Koehn (2003).

The first paper in this special issue addresses "Privacy Rights on the Internet: Self Regulation or Government Regulation?" Norman E, Bowie and Karim Jamal (2006) review an earlier empirical study (Jamal, Maier, and Sunder 2003) and combine it with information gathered in the U.K. to examine whether high traffic websites are honoring their promises to consumers regarding privacy. This is a critical ethical and economic question because privacy concerns have been shown to be a major factor in depressing the growth rate of Internet shopping (Tedeschi 2000). Moreover, the extent of keeping privacy promises by Internet sellers will help determine whether the U.S. government needs to supplement current industry self regulation, presently implemented through various "assurance seals" and privacy policies that specify the subsequent usage of any buyer information that has been gathered. Some consumer advocates have called for European style restrictions prohibiting any secondary use of information provided by consumers (Scheibal and Gladstone 2000). The authors use Kantian reasoning to establish the centrality of a consumer's right to privacy. However, based on the significantly high compliance rates by U.S. sellers in apparently honoring buyer privacy (as

\section{Laczniak \& Murphy}


demonstrated by their empirical test), government mandated regulation of privacy policies are not recommended at this time. Bowie and Jamal observe, however, that an explicit "opt-in" provision for any further usage of consumer information, beyond the original transaction, is the approach most aligned with the basic right of consumer autonomy.

In the second paper, "Online Brands and Trademark Conflicts: A Hegelian Perspective," Richard A. Spinello (2006) draws on the philosophy of George Hegel, particularly his conception of property rights, to clarify and somewhat limit the legal claims of corporations to Internet domain names that incorporate their trademarks. As Internet commerce has mushroomed, various external parties have tried to incorporate famous names into their own domain addresses in order to create confusion, divert traffic to their own sites or extract ransom from the trademarked name owners. A widely reported incident of such usurpation in a non-commercial setting was whitehouse.com (a porn site) as contrasted with whitehouse.gov, the e-mail contact address for staff serving the U.S. President. Spinello argues that Hegel's view of property appears to usefully balance the marketer's rights to trademark protection with competing consumer claims more fairly than other philosophies. For example, a reasonable person attempting to shop Wal-Mart online might well confuse Wal-Mart.org (a potentially bogus address) with Wal-Mart.com. And so, if there is a dispute about domain address rights, the trademark claims of Wal-Mart should prevail. However, using Hegelian reasoning, Spinello contends that WalMartsucks.com (a website likely critical of the firm) would not be confused by a reasonable person as the home page of the real Wal-Mart. So, in this latter case, private property rights to the disputed ether space — a legitimate forum for social criticism—ought not to be available to the corporation.

To be sure, these $B E Q$ papers are just the opening round in what should be an on-going dialog about ethical issues emanating from the marketing and technology interface. We encourage interested scholars to further address the ethical implications of questions such as:

- Is it fair for marketers to use electronic customer profiles to actively discourage transactions from customers that are projected to be unprofitable to serve?

- Is it proper for online marketers to utilize targeted price discrimination based on the past online behaviors of individual consumers without acknowledging the protocol behind the practice?

- What can be done about consumer abuses caused by international e-marketers not subject to local or national marketing regulations?

\section{Laczniak \& Murphy}


This last question raises one of the more poignant issues about the borderless world of Internet marketing. Since cyberspace is global, how can it ever be effectively regulated by governmental authorities that are geographically bound? It would seem that the universality of the web marketing world makes it critically imperative that prevailing ethical norms and values be established among netizens in order to reduce buyer exploitation and enhance transactional trust. In other words, the future fairness and justice of Internet marketing will depend far more on ethics than law. Finally, the discussion contained in this special issue of $B E Q$ does not specifically address the ethical implications involved in the use of new marketing technologies not directly connected to a web selling environment. For example, the increased sophistication, miniaturization, and lower cost of surveillance capability has added to the arsenal of marketing researchers interested in doing covert observational consumer studies (Hagerty and Berman 2003). Who will watch these consumer watchers? Ethical evaluations of these offline applications of marketing technology are needed.

In the end, marketing practitioners adopt new technology because it promises to increase the efficiency or effectiveness of exchange. Such applications imply lower costs or greater convenience for consumers. In this manner, the use of new technology has always been a driver of the material abundance available in the marketplace. But typically, new technologies bring with them some questionable and often unintended side effects. One critical role for those in the Academy interested in ethics is to identify and evaluate those side effects in terms of how they must be balanced to promote greater economic fairness and justice. A continuation of discussions contained in this issue of $B E Q$ is welcomed, encouraged and anticipated.

\section{References}

Appleby, J. 2004. "FDA Guidelines Call for Radio Technology to Control Counterfeit Drugs." USA Today (November 16): 7B.

Berson, A., S. Smith, and K. Thurling. 2000. Building Data Mining Applications for CRM (Columbus: McGraw Hill).

Borzo, J. 2004. "Something's Phishy." The Wall Street Journal (November 15): R8, R11.

Bowie, N., and K. Jamal. 2006. "Privacy Rights on the Internet: Self Regulation or Government Regulation?" Business Ethics Quarterly 16:3 (July): 323-42.

Caudill, E. M., and P. E. Murphy. 2000. "Consumer Online Privacy: Legal and Ethical Issues." Journal of Public Policy \& Marketing 19(1): 7-19.

8 Laczniak \& Murphy 
Chang, J. 2004. "Private Property." Sale and Marketing Management (December): 22-26.

Covert, J. 2004. "Down, but Far from Out." The Wall Street Journal (January 12): R5, R8.

Davidson, P. 2003. "FTC Told to Enforce Do-Not-Call List." USA Today (October 8): 1B. 2004. "Do-Not-Spam Registry Could Result in More Spam, FTC Says." USA Today (June 16): B1.

De George, R. T. 1999. "Business Ethics and the Information Age." Bentley College Center for Business Ethics/Bell Atlantic Lecture Series (March 22): 1-20.

Donaldson, T. 2001. "Ethics in Cyberspace: Have We Seen this Movie Before?" Business and Society Review 106(4): 273.

Feder, B. J. 2003. "Wal-Mart Plan Could Cost Suppliers Millions." The New York Times (November 10): 1-2, http://www.nytimes.com.

Friel, A. L. 2005. "The Spam Spat: How Will Marketers Be Affected by the Fight Against Spam?" Marketing Management (May/June): 48-50.

Goldman, E. 2003. "Opinion: Hate Spam? Just Hit Delete." http://www.TwinCities.com (August 11): $1-2$.

Gordon, J. R. 2002. "Legal Services and the Digital Divide." Albany Law Journal of Science and Technology 12: 809-19.

Grabner-Kraeuter, S. 2002. "The Role of Consumers' Trust in Online-Shopping." Journal of Business Ethics 39(1/2): 43-50.

Hagerty, J. R., and D. K. Berman. 2003. "New Battleground Over Web Privacy: Ads That Snoop." The Wall Street Journal (August 27): A1, A8.

Hajewski, D. 2003. "High-Tech ID System Would Revolutionize Retail Industry." Milwaukee Journal Sentinel (February 9): 1D, 3D.

Hays, C. L. 2004. "What They Know About You." The New York Times (November 14): section 3.

Hemphill, T. A. 2002. "Electronic Commerce and Consumer Privacy: Establishing Online Trust in the U.S. Digital Economy." Business and Society Review 107(2): 221-39.

Jamal, K., M. Maier, and S. Sunder. 2003. "Privacy in E-Commerce: Development of Reporting Standards, Disclosure and Assurance Services in an Unregulated Market." Journal of Accounting Research 41(2): 285-310.

Kelly, E. P., and H. C. Rowland. 2000. "Ethical and Online Privacy Issues in Electronic Commerce." Business Horizons (May-June): 3-12.

Kesmodel, D. 2005. "When the Cookies Crumble." The Wall Street Journal (September 12): R6. Koehn, D. 2003. "The Nature of and Conditions for Online Trust." Journal of Business Ethics

9 Laczniak \& Murphy 
43(1/2)3-19.

Kracher, B., and C. L. Corritore. 2004. "Is There a Special E-Commerce Ethics?" Business Ethics Quarterly 14(1): 71-94.

Lager, M. 2005. "CRM in an Age of Legislation," Customer Relationship Management (August): 30-35.

Lans-Retsky, M. 2004. "COPPA Sets Tone for Privacy Policies." Marketing News (March 15): 8. Linn, A. 2004. "Bugged By Spies: Imports Clog Computers." USA Today (November 1): 4D.

Loveman, G. 2003. "Diamonds in the Data Mine." Harvard Business Review (May): 109-13.

Loyle, D. 2003. "Privacy Under Scrutiny." Catalog Success (June 1); www.catalogsuccess.com, 1-7.

Mangalindan, M. 2003. "Putting a Lid on Spam." The Wall Street Journal (June 6): B1, B4.

Marshall, K. P. 1999. "Has Technology Introduced New Ethical Problems?" Journal of Business Ethics 19(1): 81-90.

McWilliams, G. 2004. "Analyzing Customers, Best Buy Decides Not All Are Welcome." The Wall Street Journal (November 8): A1, A8.

Milne, G., and A. J. Rohm. 2000. "Consumer Privacy and Name Removal across Direct Marketing Channels: Exploring Opt-In and Opt-Out Alternatives." Journal of Public Policy \& Marketing 19(2): 238-49.

Murphy, P. E., G. R. Laczniak, N. E. Bowie, and T. A. Klein. 2005. Ethical Marketing (Upper Saddle River, N.J.: Pearson Prentice Hall), 205.

Ody, Penelope. 2004. "RFID Not Ready yet for Baked Beans." Financial Times (June 23): 3.

Peace, G., J. Weber, K. S. Hartzel, and J. Nightingale. 2002. "Ethical Issues in eBusiness: A Proposal for Creating the eBusiness Principles." Business Society Review 107(1): 41-60.

Peslak, A. R. 2005. "An Ethical Exploration of Privacy and Radio Frequency Identification." Journal of Business Ethics 59: 327-45.

Richtel, M. 2004. "In Texas, 28,000 Students Test an Electronic Eye." The New York Times (November 17): 1-3, www.nytimes.com.

Scheibal, W. J., and J. A. Gladstone. 2000. "Privacy on the Net: Europe Changes the Rules." Business Horizons (May-June): 13-18.

Spinello, R. 2006. "Online Brands and Trademark Conflicts: A Hegelian Perspective." Business Ethics Quarterly 16:3 (July): 343-67.

Swartz, J. 2004. "Is the Future of E-Mail Under Cyberattack?" USA Today (June 15): 4B.

Tedeschi, B. 2000. "E-Commerce Report: Giving Consumers Access to the Data Collected

10 Laczniak \& Murphy 
About Them Online." The New York Times (July 3): C6.

11 Laczniak \& Murphy 